\title{
Bailando en el Museo Reina Sofía. El Judson Dance Theater, más allá de la danza minimalista
}

\section{Dancing in the Museo Reina Sofía. The Judson Dance Theater, beyond minimalist dance}

\author{
BLANCA MOLINA OLMOS \\ Investigadora independiente \\ blanca.moliol@gmail.com
}

Resumen: Una vez conocida la manera en que se ha introducido la danza en diversos museos del panorama internacional, así como los textos, propuestas expositivas y otras iniciativas que reflexionan sobre el papel que adquiere esta en relación con el cubo blanco; se torna apremiante explorar el contexto español, marcado por una dilatada ausencia y escasez de fuentes. Así, este artículo plantea una primera aproximación a los procesos de musealización de la danza en España.

Para ello, explora cómo se ha introducido la disciplina en el Museo Nacional Centro de Arte Reina Sofía, profundiza en su gestión en el área de colecciones y toma como objeto de estudio la Sala 104.04, Performance e Interacción. Judson Dance Theater, perteneciente a la Colección 3: De la revuelta a la posmodernidad (1962-1982).

Palabras clave: Danza, Museo, MNCARS, Judson.

Abstract: Once known the way in which dance has been introduced in various museums on the international scene, as well as the texts, exhibition proposals or other initiatives that reflect on the role that dance in relation to the white cube, it becomes urgent to explore the Spanish context, marked by a long absence and scarcity of sources. Thus, this paper presents a first approach to the processes of musealization of dance in Spain.

To do this, it explores how dance has been introduced into the Museo Nacional Centro de Arte Reina Sofía, delves into its management in the area of collections and takes as its object of study Room 104.04, Performance and Interaction as an object of study. Judson Dance Theater, part of Collection 3: From revolt to postmodernity (1962-1982).

Keywords: Dance, Museum, MNCARS, Judson.

Recibido: 9 de diciembre de 2020; aceptado: 5 de febrero de 2020; publicado: 31 de marzo de 2021. Revista Historia Autónoma, 18 (2021), pp. 183-201 e-ISSN: 2254-8726; https://doi.org/10.15366/rha2021.18.010 


\section{Introducción}

Las relaciones entre danza y museo pasan por diversas fases ${ }^{1}$, pero es a partir de la década de 1990 cuando empieza a hablarse de un giro coreográfico y la danza cobra protagonismo en los museos de todo el mundo, convirtiéndose incluso "en un referente crucial para pensar, hacer $\mathrm{y}$ curar arte visual y artes performativas" 2 .

Desde hace aproximadamente una década, se ha empezado a abordar este giro y sus consecuencias, lo que ha generado una vasta cantidad de textos y propuestas expositivas u otras iniciativas que reflexionan sobre el papel que adquiere la danza en su relación con el cubo blanco. Con base en estos procesos e investigaciones, y ante la carencia de fuentes al respecto en relación con el contexto español, surge la pregunta: ¿Cómo se han desarrollado los procesos de musealización de la danza en España?

En una primera aproximación a esta cuestión, el presente artículo tiene como objetivo realizar un análisis crítico de los procesos de musealización de la danza en el Museo Reina Sofía. Para ello, se presentará una breve revisión de la introducción y tratamiento de la danza, así como otras prácticas performativas y una profundización en la Sala 104.04, Performance e Interacción. Judson Dance Theater.

El estudio de esta sala permite intuir qué discursos propone el Museo para la danza dentro de su colección. Cabe preguntarse si se justifica que la danza esté en el museo por aquellas características que la vinculan con un estilo o movimiento producido en el arte (en este caso el minimalismo); cómo el museo la expone o los problemas que le supone exponer una práctica efímera. ¿Son los restos materiales de la danza (partituras, fotografías...) lo único que el museo puede exponer? ¿Solo se pueden generar discursos curatoriales mediante esos documentos? ¿Supone su exposición que estos se eleven a la categoría de obra de arte? ¿Va el museo a establecer una jerarquía que sitúe al documento por encima del arte en vivo?

Hablar de danza en el contexto español es hablar de precariedad, sobre todo de precariedad de fuentes. Además, acotar la búsqueda a un marco tan específico como la danza en el Museo Reina Sofía hace que aquellas sean mínimas. Aun así, se pueden destacar algunos textos que son un certero punto de partida. En primer lugar, cabe mencionar las memorias que realiza la institución anualmente. Por otra parte, es necesario reseñar La colección. Museo Nacional Centro de Arte Reina Sofía. Claves de lectura (Parte II)³, libro en el que se esboza una revisión

\footnotetext{
${ }^{1}$ Bishop, Claire, "The Perils and Possibilities of Dance in the Museum: Tate, MoMA and Whitney", en Dance Research Journal, 46 (2014), pp. 62-76. https://doi.org/10.1017/S0149767714000497

${ }^{2}$ Lepecki, André, "Introduction//Dance as a practice of contemporaneity", en Lepecki, André (ed.), Dance, Londres, Whitechapel Gallery, 2012, p. 14.

${ }^{3}$ Borja-Villel, Manuel J. et al., La colección. Parte II, Claves de lectura, Madrid-Barcelona, Museo Nacional Centro de Arte Reina Sofía-Ediciones La Central, 2013.
} 
de la Sala 104.4, e Itinerarios por la Colección. Teatro ${ }^{4}$, que permite conocer los discursos que se generan en torno a algunas obras referentes a la danza de los fondos del Museo. A estas publicaciones hay que sumar "Museo y acontecimiento" 5 y "Objetualizar la experiencia, historiar la ausencia. Notas sobre performance y museos" $"$ de Lola Hinojosa. En ellos, la responsable de la Colección de Artes Performativas e Intermedia del Museo desde 2013, orienta sobre cuáles son los rumbos que toma la institución en el tratamiento del arte en vivo. Con todo, estas fuentes son insuficientes y es necesario recurrir a la oralidad.

\section{Bailando en el Museo Nacional Centro de Arte Reina Sofía}

Para ahondar en cómo se ha introducido la danza en el Museo Reina Sofía se deben analizar sus tres áreas de trabajo: Colección, Exposiciones y Actividades Públicas.

En la Colección, las referencias más tempranas a esta disciplina se dan en el ámbito de las vanguardias. En este sentido, cabe destacar la Sala 203, La nueva cultura en España, en la que se pone en relación la sensibilidad surrealista con la cultura española a partir del trabajo de la Generación del 27 y el flamenco. En este cruce de sinergias aparecen las figuras de Vicente Escudero y La Argentina. La importancia del primero queda patente a partir de un retrato de Man Ray (Vicente Escudero, bailaor de flamenco, 1928) que lo sitúa como un referente para la vanguardia española y parisina, y también como teórico de la danza que trazó una conexión entre baile y arte en textos como Pintura que baila (1950). La Argentina aparece a través de los diseños escenográficos y de cartelería que realizó Carlos Sáenz de Tejada para los Ballets Espagnols en 1927. No obstante, en ellos cobra mayor importancia la escenografía que la propia figura de Antonia Mercé y sus influencias en el ballet del momento.

Uno de los proyectos vanguardistas multidisciplinares más paradigmáticos es El ballet triádico (1922) de Oskar Schlemmer, que se presenta en la Sala 206.02, Das Triadische Ballett se recrea en la estancia a través de los figurines y los vestuarios, a los que acompañan documentos, fotos y la hoja de sala con el programa de mano de la actuación de 1922. Todo este material

\footnotetext{
${ }^{4}$ Sánchez, José A. y Zara R. Prieto, Teatro. Itinerarios por la colección, Madrid, Museo Nacional Centro de Arte Reina Sofía, 2010.

${ }^{5}$ Hinojosa Martínez, Lola, "Museo y acontecimiento/Museum and Event", en Anuario del Departamento de historia y Teoría del Arte, 26 (2014), pp. 21-28. https://doi.org/10.15366/anuario2014.26

${ }^{6}$ Hinojosa Martínez, Lola, "Objetualizar la experiencia, historiar la ausencia. Notas sobre performance y museos", en Albarrán, Juan e Iñaki Estella (eds.), Llámalo performance: historia, disciplina y recepción, Madrid, Brumaria, 2015, pp. 23-47.
} 
llega al museo en 2009 mediante un depósito 7 , y acaba conformando la nueva visión que el director del museo, Manuel Borja-Villel, busca para las colecciones desde su llegada en $2008^{8}$.

Esta renovada aproximación se percibe sobre todo en las Colecciones 2 y 3, donde se evidencia la importancia que adquiere lo corporal y lo performativo en el arte posterior a la Segunda Guerra Mundial. Todo ello se refleja en salas como Fluxfilm Anthology (Sala 422), presentada al público en el 2015, en un contexto de masiva incorporación del audiovisual y las prácticas intermedia en el discurso curatorial ${ }^{9}$. También tiene su eco en la revalorización de figuras concretas como Alberto Greco ${ }^{10}$, introductor en el país de comportamientos procesuales que desbordan las fronteras del arte. Su obra ${ }^{11}$ fue presentada en la Sala 414, Greco y la aventura de lo real.

En la Colección 3: De la revuelta a la posmodernidad (1962-1982), lo performativo se asocia a procesos de activismo, que se introducen en el Estado español a través de Zaj, Los encuentros de Pamplona y el conceptualismo madrileño y catalán. La teatralidad va a ser otra línea discursiva clave, estando presente también, como se verá a continuación, en ámbitos artísticos más tradicionales como el escultórico.

La inauguración de este último tramo de la colección en 2011 supone un punto de inflexión en el tratamiento del arte en vivo en el Museo. Rosario Peiró, jefa del Área de Colecciones, al darse cuenta de la importancia que adquirían las prácticas performativas en dicho tramo, crea en 2013 el Departamento de Artes Performativas e Intermedia. A la cabeza de este pone a Lola Hinojosa que, ya desde 2006, formaba parte del de Cine y Vídeo. Una de las consecuencias más visibles de la creación de este departamento es el aumento de obras y archivos de performance, danza y teatro en los fondos del Museo. A nivel teórico, la primera idea que empieza a gestarse es la de intermedia ${ }^{12}$, como concepto que podría englobar todas las piezas de naturaleza heterogénea que el departamento atesora.

Hasta el momento, el Museo estaba dividido de manera muy tradicional en departamentos de escultura, pintura, vídeo, etc., y cada una de las obras vinculadas a la danza, el teatro o la performance, dependiendo de la materialidad que adquirían en la colección, se gestionaba en cada uno de estos. El nuevo departamento piensa las obras desde su inmaterialidad e inicia investigaciones para generar un corpus teórico que le permita afirmar que el Museo, "ya sea a través de objetos y documentos o de la (re)escenificación, [...] estaría capacitado para aceptar

\footnotetext{
${ }^{7}$ Museo Nacional Centro de Arte Reina Sofía, "Memoria deActividades 2009”, p. 16. «https://www.museoreinasofia. es/museo/memoria-actividades»" [consultado el 17 de mayo de 2020].

${ }^{8}$ Museo Nacional Centro de Arte Reina Sofía, "Memoria de Actividades 2008”, p. 6: “Artistas que en la historiografía tradicional podían ser considerados secundarios, derivativos o simplemente tardíos, como Oskar Schlemmer, [...] alcanzan su dimensión más compleja bajo esta nueva consideración". «https://www.museoreinasofia.es/museo/ memoria-actividades» [consultado el 15 de mayo de 2020].

${ }^{9}$ Museo Nacional Centro de Arte Reina Sofía, "Memoria de Actividades 2015", p.60. «https://www.museoreinasofia. es/museo/memoria-actividades » [consultado el 17 de mayo de 2020].

${ }^{10}$ Museo Nacional Centro de Arte Reina Sofía, "Memoria de Actividades 2010", p. 13. «https://www. museoreinasofia.es/museo/memoria-actividades» [consultado el 22 de mayo de 2020].

${ }^{11}$ Alberto Greco y su obra cobran importancia en el Museo a partir de la compra del Archivo de Alberto Greco en España.

${ }^{12}$ Hinojosa Martínez, Lola, “Objetualizar la experiencia... op. cit., p. 26.
} 
el desafío de conservar y difundir los afectos y discursos implícitos a una práctica efímera" ${ }^{13}$. En este sentido, se trabaja a través de las ideas de Amelia Jones, que ampara la capacidad del museo de crear discursos y dar a conocer la performance a través del documento ${ }^{14}$. Al mismo tiempo, se cuestiona la jerarquía que esta autora genera entre el documento y el arte en vivo, y que podría llevar a la fetichización del primero. Esta idea contrasta con las de Rebecca Schneider, que reflexiona sobre cómo lo efímero no tiene por qué estar confrontado con la idea de permanencia intrínseca a la colección, pues cualquier acción efímera se retiene en la memoria y es transmitida de un cuerpo a otro o mediante la reescenificación ${ }^{15}$. Un posible acercamiento entre ambas posturas y las respuestas a las preguntas que albergan se encuentra en el concepto de archivo acuñado por Foucault:

\begin{abstract}
El archivo que intento definir puede ser material o corporal. [...] Un archivo que, si seguimos a Michel Foucault, no entenderemos como un simple conjunto de documentos transmisores de memoria y testimonio de un pasado, ni tampoco haremos referencia con dicho término a la institución que los guarda. El archivo, [...] se refiere a la posibilidad de generar enunciados, entendidos como acontecimientos discursivos. ${ }^{16}$
\end{abstract}

Estas reflexiones han llevado al Museo a engrosar sus colecciones con obras que combinan el soporte documental con su presentación en vivo; pero no se ha hecho efectiva su exposición debido a la difícil gestión, sobre todo económica, que implica el mantenimiento de una obra en vivo en sala. Sin embargo, estos planteamientos sí tienen cabida en las exposiciones temporales, que ofrecen un marco conceptual del que se puede desprender este tipo de prácticas sin que estas tiendan a la espectacularización.

La danza se cuela en ocasiones en exposiciones que abordan temas muy diversos, sin embargo, rara vez sucede que protagonice una muestra o que aparezca en vivo integrada en el dispositivo de la retrospectiva. Podríamos hablar solo de dos casos aislados.

De la primera de las situaciones, el único ejemplo es La noche española. Flamenco, vanguardia y cultura popular, 1865-1936 (20 dic. 2007-24 mar. 2008), comisariada por Patricia Molins y Pedro G. Romero. La exposición plasma una evolución del flamenco y rastrea qué intelectuales o artistas toman este arte como inspiración. Es en 2013 cuando se produce el segundo caso, y la danza en vivo se introduce en el dispositivo de la exposición temporal \pm 1961 . La expansión de las artes (19 jun.-28 oct. 2013), comisariada por Julia Robinson y Christian Xatrec. La muestra toma 1961 como el año en el que diversos artistas empiezan a relacionarse entre sí y a desarrollar proyectos multidisciplinares, y se constituye principalmente a partir de

\footnotetext{
${ }^{13}$ Ibidem, p. 47.

${ }^{14}$ Jones, Amelia, "Presence in Absentia. Experiencing Performance as Documentation", en Art Journal, 56 (1997), pp. 11-18. https://doi.org/10.2307/777715

${ }^{15}$ Schneider, Rebecca, "Los restos de lo escénico (reelaboración)", en De Naverán, Isabel (ed.), Hacer historia. Reflexiones desde la práctica de la danza, La Coruña-Barcelona, Centro Coreográfico Galego- Institut del TeatreMercat de les Flors, 2010, p. 176.

${ }^{16}$ Hinojosa Martínez, Lola, "Museo y acontecimiento... op. cit., p. 26.
} 
material de archivo y algunas obras objetuales. En ella adquieren protagonismo figuras clave para la historia de la danza, como Simone Forti y sus Dance Constructions. Precisamente, el interés en la exposición radica en estas piezas que se sitúan en un espacio que hace referencia al loft de Yoko Ono, en el que, en la primavera de 1961, La Monte Young organiza una serie de conciertos. Simone Forti participa en ellos con el programa Five Dance Constructions and Some Other Things, compuesto por: Huddle, Slant Board, Platforms y Accompaniment for La Monte's 2 sounds (without La Monte's 2 sounds) y Censor. Estas piezas no solo se presentan a través de sus estructuras de madera, sino que todos los días, entre las 12:00 h y 20:00 h, se activan por performers delegados.

Ambas exposiciones tienen muchos puntos de encuentro con las investigaciones llevadas a cabo desde Colecciones y dejan ver el trabajo estrecho que se produce entre ambas áreas. El primero de los ejemplos conecta con la Sala 203, anteriormente abordada, en la que se pone en relación el flamenco con las vanguardias. Sobre todo, las relaciones abundan en el segundo ejemplo. En primer lugar, en \pm 1961 . La expansión de las artes, la partitura cobra una importancia capital. Esta es considerada un elemento muy trabajado desde Colección y que el director considera clave ${ }^{17}$ como contenedor de un evento. Además, el Museo tiene especial interés en las piezas de Forti, que intentó comprar, pues había puesto esfuerzos en que, entre la coreógrafa y los bailarines, se hubiese dado un proceso de transmisión, apelando a las ideas de Schneider y del cuerpo como archivo de Lepecki ${ }^{18}$. Así, si se volvían a activar estas piezas había alguien que fuese archivo de las mismas ${ }^{19}$.

Sin embargo, y pese a los ejemplos anteriores, donde más presencia adquiere la danza en el Reina Sofía es a través de las actividades organizadas por el Departamento de Actividades Públicas. La danza empieza a introducirse en el Reina Sofía a través de estas a finales de la década de 1990, a partir de soportes más asequibles — como el vídeo-, en ciclos anuales de vídeodanza organizados, entre 1995 y 1998, por Nuria Font: Coreografiar para la cámara (1995), Bailando con vídeos (1996), En dos dimensiones: Danza en pantalla (1997) y Filmar la danza: principio y fin de siglo (1998). La relación entre la danza y los medios audiovisuales se seguirá presentando en actividades como Cuerpos desplazados. Trazas audiovisuales entre la danza y la performance, 1963-1986, ciclo de nueve sesiones comisariado por Gabriel Villota en 2015. La danza en vivo se presenta por primera vez en el Museo en 2003, cuando se realiza Panoramix de La Ribot. El director del momento, Juan Manuel Bonet, se mostró reacio a que la actividad se llevase a cabo y solo accedió a dejar el Palacio Velázquez entre dos exposiciones, por lo que esta se concibió fuera del espacio del Museo y de sus líneas narrativas. Además, el

\footnotetext{
${ }_{17}$ Valencia Plaza, "Manuel Borja-Villel, entrevista realizada por Carlos Garsán”, «https://valenciaplaza.com/ manuel-borja-villel-ya-no-es-importante-poseer-todas-las-cosas-sino-generar-relatos»" [consultado el 21 de junio de 2020]: "Gran parte del arte es efímero y, por lo tanto, quien tiene la 'partitura' tiene la clave".

${ }^{18}$ Lepecki, André, "El cuerpo como archivo: El deseo de Recreación y las supervivencias de las danzas", en De Naverán, Isabel y Amparo Écija (eds.), Lecturas sobre danza y Coreografí, Madrid, Artea Editorial, 2013, pp. 59-81.

${ }^{19}$ Hinojosa Martínez, Lola, entrevista realizada por Blanca Molina Olmos, Murcia-Madrid, 30 de junio de 2020.
} 
proyecto fue gestionado por la propia La Ribot, Paz Santa Cecilia y Soledad Lorenzo, con la financiación de la Comunidad de Madrid. Otro hito importante en relación con la danza que se produce en el Departamento de Actividades Públicas es la creación de un Programa de Artes en Vivo en $2009^{20}$.

Gran parte de la danza que se presenta en este contexto evidencia cierta relación con los discursos planteados desde Colecciones, por ello, la presencia en las actividades de coreógrafos que participaron de la experiencia del Judson Dance Theater es frecuente. También, se vincula a exposiciones temporales que tengan o no tengan que ver con la danza o en relación con jornadas, ciclos y conferencias. Por ejemplo, durante el 2017 se llevó a cabo la exposición Piedad y terror en Picasso. El camino a Guernica y, en el marco de esta, se presentaron las piezas de danza Deep Song de la Compañía Martha Graham y Gernika-Guernica de Kukai Dantza. Ese mismo año, en torno al ciclo Podría quien te recuerda... Cuerpo, archivo y memoria, se reunieron distintas propuestas de danza y performance contemporáneas: como Envoltura, que ofrece un recorrido por cuatro piezas breves creadas por distintos artistas. Otro ciclo importante por el tipo de propuestas que acogió es Danza años 80. Primeros pasos de la danza contemporánea en España. Asociado a este ciclo, diversos comisarios que impartieron conferencias en él seleccionaban una pieza para exponer en sala. Entre las obras seleccionadas se encontraban: Socorro! Gloria! (1991) y 13 Piezas distinguidas (1993-1994) de La Ribot, Ahí va Viviana (1988) de Bocanada, Solos (1990) de Vianants danza, Kolbebasar (1988) y El Mar (1989) de Angels Margarit con Mudances, y Lugares Intermedios (1993) de Olga Mesa. La danza también aparece de manera eventual el Día Mundial de la Danza, o a partir de la colaboración con festivales u otras instituciones con las que se establecen convenios para facilitar la gestión. En el caso de no ligarse a ninguno de ellos, el arte en vivo - como indica Lola Hinojosa - siempre debe producirse en forma de intervalos, entendidos al modo que lo hacía Dziga Vertov, es decir, como muestras que aunque parezcan aisladas se hacen eco de investigaciones importantes para el Museo o abren otras nuevas ${ }^{21}$.

Al mismo tiempo, Hinojosa afirma que la conexión con Actividades Públicas no es tan estrecha como la que se produce entre Colección y Exposiciones $^{22} \mathrm{y}$, en ocasiones, se deja ver en las propuestas los intereses de las personas encargadas de la gestión de estos eventos, a menudo, comisarios independientes que trabajan con este departamento. Esto sigue sucediendo en la actualidad, cuando la gestión de la danza la asume Isabel de Naverán. Uno de los temas en los que se centra es en las posibilidades de la danza y el cuerpo como dispositivos de memoria y recuperación de la historia. Sus intereses conectan con los del Museo que, desde 2018, establece como una de las líneas-fuerza del Programa de Actividades Públicas las cuestiones relativas a la memoria y la revisión de las historiografías dominantes.

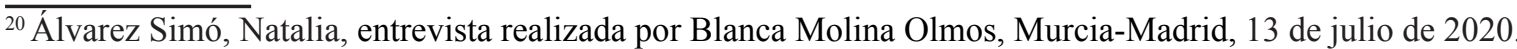

${ }^{21}$ Hinojosa Martínez, Lola, "Museo y acontecimiento... op. cit., p. 25.

${ }^{22}$ Hinojosa Martínez, Lola, entrevista... op. cit.
} 
Además, la mayoría de las propuestas de danza siguen emplazándose en el auditorio del Museo, es decir, en la caja negra tradicional. Solo se han ocupado otros espacios en algunas ocasiones como los Events realizados por la Merce Cunningham Dance Company (2009), 20 Dancers for the XX Century de Boris Charmatz (2016), la actuación de la compañía Kukai Dantza (2017), todos ellos en las galerías del Museo, y la intervención de Israel Galván en la Biblioteca (2019).

\section{Judson Dance Theater: más allá de la danza minimalista}

La Colección 3: De la revuelta a la posmodernidad (1962-1982), emplazada en la primera planta del Edificio Nouvel, es, hasta la fecha, el último tramo de las colecciones del Museo Reina Sofía. Presentada en 2011, fue comisariada por Manuel Borja-Villel, director del museo; Rosario Peiró, directora del Área de Colecciones; y Jesús Carrillo, a cargo del Departamento de Actividades Culturales entre el 2008 y 2014. La inauguración de este tramo debe emplazarse dentro del nuevo proyecto museográfico planteado por Borja-Villel tras su llegada al Museo en 2008. Este proyecto implica una tarea de estudio y reinterpretación de los fondos de la institución que se materializó en 2009 en las relecturas de los dos primeros tramos. Dicha relectura se refleja aquí en una nueva presentación de las colecciones mediante itinerarios que generan un "mapa de centros múltiples", alejados del canon hegemónico ${ }^{23}$.

Entre los procesos históricos, sociales y artísticos que se producen en las tres décadas que recorren las salas de este nuevo tramo, se cuela el interés de los artistas por la teatralidad, siendo las relaciones entre los cuerpos y de estos con el espacio, vectores clave desde los que parten diversos procesos estéticos más allá del ámbito escénico. Estas ideas en torno a la teatralidad cumplen un papel fundamental en (este 'en' es lo que faltaba en la redacción anterior, he tenido que leerlo varias veces para darme cuenta) las salas 104.03, Los espacios inespecificos: arte en los Estados Unidos y la 104.04, Performance e interacción: Judson Dance Theater, de las que nos ocuparemos a continuación.

En la primera de estas salas, se exponen Magnesium Copper Plain (1969) de Carl Andre; The Nominal Three (To William of Ockham) (1963) de Dan Flavin y Wall Drawing \#47 (1970) de Sol LeWitt. A través de ellas se presenta la escultura minimalista como ejemplo de una práctica no escénica que se acerca a la teatralidad. En este sentido, Rosalind Krauss afirma que esta "tiene que ver con el despliegue de los cuerpos en el espacio"24 en relación con las convenciones

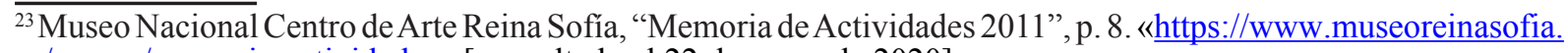
es/museo/memoria-actividades»" [consultado el 22 de mayo de 2020].

${ }^{24}$ Krauss, Rosalind, Pasajes de la escultura moderna, Madrid, Akal, 2002, p. 9.
} 
escénicas. Sobre este mismo hecho redundan los planteamientos que Michael Fried esgrime en “Arte y objetualidad" (1967), fundamentales en la creación del discurso curatorial ${ }^{25}$. Fried hace una crítica a la escultura minimalista acusándola de caer en la teatralidad por su adhesión a la objetualidad ${ }^{26}$, la temporalidad ${ }^{27} \mathrm{y}$, sobre todo, sus intenciones de interpelar al espectador ${ }^{28}$.

Los nuevos caminos hacia los que derivaron los procesos escultóricos se relacionan con cómo la teatralidad es entendida en las décadas de 1960 y 1970 por diversos artistas que compartían características comunes: "una indagación sobre la percepción y la experiencia directa, la apertura de la forma hacia la participación, la improvisación y el azar, la colaboración como autoría, la regla como forma, la cotidianidad como materia" ${ }^{29} \mathrm{y}$, sobre todo, la disolución de las fronteras entre las disciplinas artísticas, pero también entre estas y la vida. Todos estos nuevos modos de hacer encajan a la perfección en las propuestas que se están dando desde la danza posmoderna, estilo aparejado al Judson Dance Theater, que recibe su nombre de la Judson Memorial Church donde, entre 1962 y 1964, se llevaron a cabo una serie de talleres abiertos en los que participaron artistas de diversos ámbitos.

En el Museo, el trabajo del Judson se presenta en la sala a través de cuatro piezas de Yvonne Rainer, Trisha Brown y Simone Forti, habiendo descartado obras de integrantes masculinos como Robert Morris, que participó del trabajo del grupo $^{30}$ y de la escultura minimalista, lo que podía haber hecho de enlace entre ambos. Esta decisión responde a que el Museo busca una genealogía alternativa de las neo-vanguardias norteamericanas, ensombrecidas por las historias canónicas del arte contemporáneo (minimalismo, conceptual y pop), que acentuase la importancia de la danza y, sobre todo, la importancia de las artistas mujeres. Este es el motivo por el que también sus vídeos se exponen a gran escala en una proyección que ocupa gran parte del espacio ${ }^{31}$. Es decir, se intenta presentar a las autoras de este colectivo no como artistas subsidiarias y en una relación jerárquica con los escultores minimalistas, sino como un grupo de pleno derecho.

Las obras que alberga la sala se ajustan a la descripción que, en 1975, el crítico Michael Kirby utilizó en The Drama Review:

En la teoría de la danza posmoderna, el coreógrafo no se preocupa por los aspectos visuales de la obra. El interés está en el interior: el movimiento no se elige por sus características, sino por el resultado de ciertas decisiones,

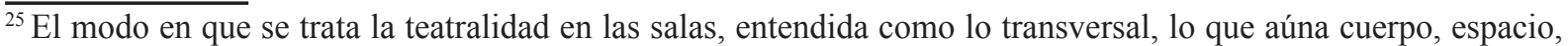
texto..., lleva la impronta del director del museo, muy interesado en estos conceptos.

${ }^{26}$ Fried, Michael, "Arte y objetualidad" (1967), traducido por Benavente, Carolina, Brevis, Macarena y Cortés, Carolina en Escáner cultural, 147 (2012), p. 7: "La adhesión literalista a la objetualidad no es más que la defensa de un nuevo género de teatro". «http://revista.escaner.cl/node/6187» [consultado el 25 de agosto de 2020].

${ }^{27}$ Ibidem, p. 17: "La preocupación literalista por el tiempo [...] es, sugiero, paradigmáticamente teatral".

${ }^{28}$ Ibidem, p. 8: "Le preocupan las circunstancias concretas en las que el espectador se encuentra con la obra literalista".

${ }^{29}$ Sánchez, José A. y Zara R. Prieto, Teatro... op. cit., p. 88.

${ }^{30}$ Robert Morris participó en las veladas de la Judson Memorial Church, donde entre 1962 y 1965, coreografió War (1962), Arizona (1963), 21.3 (1964), Site (1964), Check (1964) y Waterman Switch (1965). También hizo aportaciones teóricas a la danza posmoderna en "Notes on Dance" (1965).

${ }^{31}$ Hinojosa Martínez, Lola, entrevista... op . cit.
} 
objetivos, planes, esquemas, reglas, conceptos o problemas. Es válido cualquier movimiento que ocurra durante la actuación, siempre que se cumplan los principios de límite y control. ${ }^{32}$

Esta definición es escasa para comprender la danza posmoderna en general, pero podemos asociarla a una de las tres vertientes que Sally Banes presenta en la introducción de Terpsicore in Sneakers: la analítica ${ }^{33}$. Las piezas de la sala no solo encajan formal y cronológicamente en esta vertiente, sino que las lecturas que el Museo privilegia para construir el discurso curatorial acentúan aquellas características de la misma, que entroncan con los principios de la escultura minimalista.

Trio A, de Yvonne Rainer, se muestra en la versión rodada por Robert Alexander el 12 de agosto de 1978, aunque esta se presentó por primera vez el 10 de enero de 1966 en la Judson Memorial Church bajo el nombre de The Mind is a Muscle. Las características de esta pieza que el Museo pone de relieve son las que se destacaron en la primera lectura minimalista que se hizo en el libro de Gregory Battcock, Minimal Art: A Critical Anthology ${ }^{34}$. Su interpretación resalta como principal aportación de Trio $A$ la negación del clímax, las variaciones, la ausencia de representación y expresión, el virtuosismo y las cualidades posturales y arquitectónicas de la danza. Esto deja solo un movimiento puro, que aun así, no se ve exento de complejidad y necesita precisión y resistencia para su ejecución, lo cual implica un uso de la energía equivalente en todas las partes, la repetición, el uso de movimientos sencillos cercanos a las tareas... Todas estas características, tanto en el volumen mencionado como en la sala, se trazan paralelamente a las de la escultura minimalista y su rechazo hacia el trabajo del artista, la relación jerárquica de partes, la textura, el ilusionismo, la complejidad, el detalle y la monumentalidad; pero también en analogía con la fabricación industrial, las formas unitarias, los módulos, la superficie ininterrumpida, la literalidad, la simplicidad y la escala humana. También se pone en paralelo el Manifiesto del $n o^{35}$, publicado por esta coreógrafa en 1965, con la estética de la negación

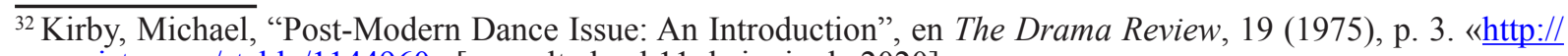
www.jstor.org/stable/1144960» [consultado el 11 de junio de 2020].

${ }^{33}$ Banes, Sally, Terpsichore in Sneakers: Post-modern Dance, Wesleyan, University Press, 2011, p. xiii-xxxix. Sally Banes en la introducción de Terpsichore in Sneakers presenta tres vertientes dentro de la danza posmoderna: la vertiente disidente, que se desarrolla en paralelo al trabajo inicial del grupo entre 1962 y 1968; la vertiente analítica, es la más cercana al minimalismo; por último, la vertiente metafórica o metafísica que vuelve sobre una danza en la que la metáfora es importante, adelantándose a las tendencias de danza teatro de los 80 . Estas dos últimas vertientes se desarrollan en los 70, a partir de un trabajo más autónomo de cada artista.

${ }^{34}$ Rainer, Yvonne, "A Quasi Survey of Some 'Minimalist' Tendencies in the Quantitatively Minimal Dance Activitiy Midst the Plethora or an Analysis of Trio A", en Battcock, Gregory (ed.), Minimal Art: A Critical Anthology, Nueva York, E. P. Dutton \& Co, 1968, pp. 290-299.

${ }^{35}$ Rainer, Yvonne, "Some Retrospective Notes on a Dance for 10 People and 12 Mattresses Called 'Parts of Some Sextets', Performed at the Wadsworth Atheneum, Hartford, Connecticut, and Judson Memorial Church, New York, in March, 1965", en The Tulane Drama Review, 2 (1965), p. 178: "No al espectáculo, No al virtuosismo, No a las transformaciones y a la magia y al hacer creer, No al glamour y a la trascendencia de la imagen de la estrella, No a lo heroico, No a lo anti-heroico, No al imaginario basura, No al involucrarse de intérprete o del espectador, No al estilo, No al camp, No a la seducción del espectador mediante trucos del intérprete, No a la excentricidad, No a moverse o ser movido". https://doi.org/10.2307/1125242
} 
desarrollada por ciertos artistas minimalistas, y que se refleja en las palabras de Robert Morris recogidas en Continuous Project Altered Daily:

Cuando corté la madera contrachapada con mi Skilsaw, pude escuchar, bajo un sonido ensordecedor, un "no" rotundo y renovador que resonaba entre las cuatro paredes: no a la trascendencia y los valores espirituales, no a la escala heroica, a las decisiones angustiosas, a la narrativa histórica, al artefacto valioso, a la estructura inteligente, experiencia visual interesante. ${ }^{36}$

En segundo lugar, encontramos Primary Accumulation (1972), perteneciente a la serie Accumulations, desarrollada por Trisha Brown, basada en sistemas matemáticos de acumulación: $1 ; 1,2 ; 1,2,3 ; 1,2,3,4 \ldots{ }^{37}$ La pieza se asocia muy claramente a dos trabajos minimalistas de la Sala 104.03: Wall Drawing \#47 de Sol LeWitt y Magnesium Copper Plain de Carl Andre. La primera de ellas se aproxima a la coreografía de Brown al ser un sistema conceptual que se materializa a partir de módulos matemáticos que van repitiéndose, la división del muro en 15 franjas de igual tamaño. Ambas obras ponen el foco en el cuerpo humano, pues en Primary Accumulation se "presenta el cuerpo humano como sujeto y objeto de la investigación" ${ }^{38}$ y en Wall Drawing \#47 "mientras el dibujo se mantiene inalterado, su localización y escala exigen el movimiento del cuerpo en busca del ángulo que permita contemplarla por completo" ${ }^{39}$. Carl Andre y Trisha Brown tienen como primer punto de unión el rechazo de la verticalidad, pues sus obras se desarrollan en un plano horizontal. Asimismo, sendas obras se construyen mediante unidades simples, que generan sistemas mentales y centran la atención en las propiedades, en Magnesium Copper Plain, las propiedades del magnesio y el cobre que dan color a la obra; en Primary Accumulation, la sencillez y precisión, inseparables una de otra, y de la repetición, pues los movimientos debían ser sencillos para no perder la precisión en las sucesivas repeticiones.

Los movimientos generados en las piezas de la serie Accumulation parten de sus dibujos de 1973, que también se exponen en la sala. A través del tratamiento que Trisha Brown da a estos dibujos, se puede entender que en ambas salas "el arte tiene que ver con los cuerpos en el espacio, sea ese espacio el papel, la calle o el museo" ${ }^{40}$, pues, como ella misma explica, no son únicamente partituras o dancegrams, sino que cada línea tiene la capacidad de "esculpir el espacio y una dimensionalidad, lo que tiene mucho que ver con el cuerpo"41. En ellos, desarrolló un vocabulario que permitiese la relación entre signo y movimiento, creando un alfabeto en el que se equiparan letras a movimientos. Pero estas partituras no pueden considerarse únicamente

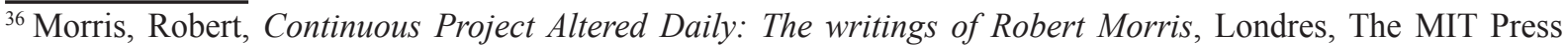
Cambridge, 1993, pp. 263-265.

${ }^{37}$ Banes, Sally, Terpsichore in Sneakers... op. cit., p. 82.

${ }^{38}$ Ibidem, p. 84.

${ }^{39}$ Borja-Villel, Manuel et al., La colección... op. cit., p. 96.

${ }^{40}$ Ibidem, p. 10.

${ }^{41}$ Brown, Trisha y Hendel Teicher, Trisha Brown-Danse, Précis de Liberté, Marseille, RMN, 1998, p. 5, citado en Shirley Dai, Lu, Dancing and Drawing in Trisha Brown's Work: A Conversation Between Choreography and Visual Art, tesis doctoral, Barnard College, 2016, p. 22.
} 
un reflejo de esta relación, sino que son en sí mismas una forma de creación. Esto se debe a su formación con Robert Dunn en el Merce Cunningham Studio, del que tomó, entre otras cosas, la importancia del papel de la partitura como documentación y forma de creación.

Por último, sobre Solo No.1 de Forti (1974) destacan dos cuestiones muy importantes para las posibles lecturas que pueden hacerse de la sala: la asimilación de la danza con la escultura y la importancia del espectador. En Claves de lectura, cuando se aborda esta pieza, se da importancia al trabajo de la cámara: "el papel del público lo cumple la cámara que, en sus movimientos de aproximación y alejamiento de la artista, penetra en su espacio y dialoga con las evoluciones zoomórficas de la coreografía" ${ }^{42}$. Esta conexión con el espectador es central para el Museo, que afirma que los debates sobre el espectador se ponen en relación con la danza cuando esta empieza a plantearse "como escultura y al ejecutante como objeto, en una intersección con las propuestas minimal”43.

Todas las obras expuestas en la Sala 104.04 podrían recibir el apelativo de danza minimalista, que desarrolla consigo un nuevo concepto de espectador al que Amparo Écija se refiere como espectador minimalista: "alguien dispuesto a entrar en la estructura conceptual del movimiento" ${ }^{44}$. Este nuevo espectador, también se requería debido a la heterogeneidad de espacios en los que se llevaban a cabo las coreografías del Judson (gimnasio, iglesia, galerías, espacios públicos...), en los que se producía una ruptura de la frontalidad, las jerarquías y el espectador debía tomar decisiones.

Trisha Brown piensa Primary Accumulation desde un punto de vista cenital y siente que el público debía estar en el techo ${ }^{45}$, una perspectiva similar a la que debe adoptar el espectador al caminar sobre Magnesium Copper Plain. Al hacerlo, este toma consciencia de su cuerpo respecto al espacio y en relación con la obra. En Trio A, la neutralidad de los movimientos implica directamente al espectador, "que tiene como consecuencia un tipo de emoción intelectual provocada por la claridad del lenguaje" $"$. Wall Drawing \#47, como se ha mencionado, requiere de la activación del espectador para su contemplación.

Pero ¿vamos a hablar solo del espectador minimalista? ¿Y el espectador actual, el visitante de la sala? ¿Qué papel adopta al ponerse frente a las proyecciones de las obras? En esta última pregunta está el principal contraste que se da entre el espectador minimalista y el visitante, que se sitúa de frente a las proyecciones, es decir, en la sala se produce una vuelta a la frontalidad. En segundo lugar, es preciso destacar que los tres vídeos tienen una duración interna propia que es distinta del tiempo de visita del espectador. Este, en su recorrido por la sala, no se detiene el tiempo suficiente frente a ellos, a lo que se suma que las coreografías se proyectan de manera

\footnotetext{
${ }^{42}$ Borja-Villel, Manuel J. et al., La colección... op. cit., p. 103.

${ }^{43}$ Ibidem, p. 95.

${ }^{44}$ Archivo ARTEA, Écija, Amparo, "El espectador minimalista”, 2011. «https://n9.cl/1dqs4 » [consultado el 27 de junio de 2020].

${ }^{45}$ Banes, Sally, Terpsichore in Sneakers... op. cit., p. 83.

${ }^{46}$ Archivo ARTEA, Écija, Amparo, "El espectador... op. cit.
} 
sucesiva en la misma pared. Entonces, el espectador no solo no ve una coreografía al completo, sino que no ve dos de las cuatro obras expuestas en la sala, y la visión global de todas sus piezas queda interrumpida. Además, que las coreografías estén en esta especie de bucle, impide que cuando el público entre en la sala reconozca cuál de ellas está viendo, pues esto solo se anuncia en el comienzo de cada una y el visitante no siempre las aborda desde esta parte.

La Sala 104.04 es un ejemplo de los problemas derivados de la exposición de cine y obras audiovisuales en el Museo Reina Sofía. En varias estancias se proyectan cortos y películas cuya duración es inabarcable para el espectador, que, además, no encuentra condiciones físicas (sillas o bancos, un sonido e iluminación adecuados) para seguir la proyección prolongadamente. Esto conduce hacia un segundo contraste entre el espectador minimalista y el visitante del museo o, mejor aún, entre unas piezas hechas para el espectador y una sala hecha para las piezas. Mientras que las coreografías realizadas en el contexto del Judson privilegian la experiencia del público, parece que la experiencia del espectador queda relegada a un segundo plano en la sala, desplazada por la dimensión simbólica de las piezas dentro del trabajo de este movimiento o de la historia del arte en general. En un segundo momento de reflexión, se podría subvertir este pensamiento y entender las proyecciones como parte de un conjunto de relaciones que se producen entre las obras y que será completado, en mayor medida, cuanto mayor sea la iniciativa del espectador en ver la película entera, buscar otras referencias... convirtiéndo sus intenciones en parte fundamental de su experiencia.

A pesar de que la asimilación entre la danza y la escultura minimalista que se produce en estas salas no pretende fomentar vínculos basados en relaciones jerárquicas, finalmente se crea una asociación que pareciera validar "las artes del teatro y la danza basadas en espectáculos: sucias, impuras e históricamente feminizadas" ${ }^{47}$, equiparándolas con la escultura, acercándola a los discursos de eternidad y la autoría singular, y alejándola de las asociaciones con el entretenimiento y el espectáculo. Esta premisa se ancla en la apreciación de tres problemáticas conectadas entre sí.

La primera de ellas es la restricción de la representación de la danza posmoderna a la danza analítica, que deja de lado, siguiendo el esquema de Banes, a las vertientes disidente y metafísica. De esta manera no se plasma la heterogeneidad del movimiento, y se olvidan ciertos rasgos que permitirían volver la vista hacia la disciplina de la danza, y, además, generar nuevas conexiones con las piezas de la Colección 3 expuestas en las salas adyacentes a la del Judson.

En segundo lugar, la falta de profundidad en el tratamiento de la danza como medio y tradición. El Museo, a partir del esquema publicado por Rainer en la revista Live ${ }^{48}$, destaca las influencias híbridas de la danza posmoderna, incluyendo en su genealogía, tanto a artistas visuales como a sus antecedentes provenientes del mundo de la danza más inmediatos, Merce

\footnotetext{
${ }^{47}$ Schneider, Rebecca, Performing Remains: Art and war in times of theatrical reenactment, Londres, Routledge, 2011, p. 130. https://doi.org/10.4324/9780203852873

${ }^{48}$ Citado en Museo Reina Sofía, "Sala 104.04, Performance e Interacción. Judson Dance Theater”, «https://www. museoreinasofia.es/coleccion/sala/sala-10404) [ [consultado el 23 de junio de 2020].
} 
Cunningham o Anna Halprin. Sin embargo, no se profundiza en esa herencia, incluso se deja de lado una de las razones de ser de la danza posmoderna: la reacción contra todos los esquemas producidos en la danza anterior, especialmente en la danza moderna. En este sentido, es pertinente aclarar que el término danza posmoderna se utiliza cronológicamente, pero también por su rebelión contra el estilo moderno y sus representantes. Posicionarse en la necesidad de dar un tratamiento adecuado al propio medio, no se está rechazando la idea de que las coreografías se muevan en un terreno interdisciplinar, ni los intercambios de ida y vuelta que se producen entre esta disciplina y el resto de las artes; sino que se propone una mirada hacia la historia de la danza y un acercamiento hacia posiciones que enfatizan las huellas y particularidades de esta práctica, para evidenciar así los aportes y rescatar ciertos rasgos presentados a continuación.

La última de estas problemáticas se aprecia al profundizar en las conexiones que el Museo genera para trazar un discurso entre las salas ya abordadas, la Sala 104.05 que acoge To Each Concrete Man (1974) de Ree Morton y la Sala 104.06, Espacios de vida: las políticas del arte povera. El arte que se presenta en ambas salas comparte contexto con el minimalismo y se relaciona con este movimiento presentándose como una reacción al mismo. Por un lado, el arte povera como crítica a la técnica y la industrialización de la que participa el minimalismo, fomentando una lectura política de sus obras, muy ligadas a su contexto. De otro, la instalación de Ree Morton, que también arremete contra la frialdad industrial y genera visiones cercanas a propuestas performativas en relación con discursos feministas, frente a la escultura minimalista eminentemente masculinizada. Si se deja de pensar el minimalismo y la danza como un todo dentro del Museo, estas lecturas podrían ampliarse generando nuevas relaciones. Incluso permitirían desbordar las fronteras del arte, que se lanza a la calle y se fusiona con la vida, participando de la disidencia y el activismo político; relaciones que el museo fomenta desde diversas perspectivas.

Muchas de estas características de la danza analítica de la década de 1970, que se ponen en relación con el arte minimalista, se habían desarrollado con los primeros pasos de la danza posmoderna y son parte de un proceso de democratización más amplio. Yvonne Rainer explicaba que, en la danza anterior "si caminabas como un bailarín, caminabas como si fueses una reina, un aristócrata, un personaje, alguien que fuese más que ordinario, más que humano"49. La danza posmoderna pretende alejarse de los rasgos que elevan a los bailarines a la altura de seres extraordinarios. Se produce entonces una democratización de los cuerpos: cualquiera puede bailar y los coreógrafos trabajan con personas que no tienen formación en danza, el público, personas con corporalidades alternativas, etc. Trio A, anteriormente explicada desde

\footnotetext{
${ }^{49}$ Banes, Sally, "Gulliver's Hamburger. Defamiliarization and the Ordinary in the 1960s Avant-Garde", en Banes, Sally (ed.), Reinventing dance in the 1960's: Everything was Possible, Wisconsin, The University of Wisconsin Press, 2003, p. 3.
} 
la perspectiva analítica, se acerca a esta intención democratizadora, pues Rainer la construye a partir de movimientos sencillos y asequibles para todo el mundo ${ }^{50}$.

Esta apertura del movimiento lleva a la incorporación de acciones cotidianas. Esto supone su transformación en un "heroísmo de la gente común" 51 y que acciones como correr o andar diesen lugar a obras que son emblema de la generación, como Proxy (1961) de Steve Paxton o We Shall Run (1963) de Rainer. Esta idea está íntimamente ligada a la que presenta Lucy Lippard al referirse a la abstracción excéntrica, concepto que se "benefició del descubrimiento del siglo xix de que la dulzura, la luz y el heroísmo no eran los únicos válidos para el arte" 52 , y a partir del cual se pueden establecer relaciones entre las obras de ambas salas.

Además de movimientos, los participantes del Judson llevan a escena objetos cotidianos, utilizándolos como sustitutos del cuerpo, complementos del mismo, objetos animados, etc. ${ }^{53} \mathrm{La}$ introducción de lo cotidiano en el contexto artístico implica un proceso de desfamiliarización, que permite apreciar cualidades de los objetos que diariamente pasan desapercibidas. Esto mismo se produce en To Each Concrete Man de Ree Morton, en la que los objetos de la instalación, a pesar de ser sacados del mundo natural, por la iluminación o su colocación en la sala, van a rozar el animismo. Este uso pretende evocar una respuesta sensitiva en el espectador, que se convierte en una pieza central, y recorre el espacio tomando conciencia de él y de la relación que se establece entre lo natural, lo ritual, lo fantástico y/o lo teatral.

Las reacciones sensitivas también conectan con el concepto de abstracción excéntrica e invaden las obras de Ree Morton y Primary Accumulation de Trisha Brown, a la que Banes aplica este término haciendo hincapié en la respuesta sensitiva que ciertas connotaciones sensuales de la danza implican para el espectador y la propia $\operatorname{artista~}^{54}$, lo que enlaza con ciertas cuestiones de género, abordadas a continuación. Otra de las características que pueden compartir las obras con las que se relaciona la abstracción excéntrica es que tienden al "anticlímax", algo patente en las piezas coreográficas basadas en patrones repetitivos de movimiento.

Este giro de contexto que produce en escena - los objetos y movimientos cotidianos invaden el contexto artístico-, se da a la inversa cuando la danza invade el espacio ordinario. Primary Accumulation se realiza en parques, en la plaza del Edificio McGraw-Hill en Nueva York, en galerías de arte... Esta necesidad de salir hacia afuera se podría relacionar con la inespecificidad del espacio de la pintura minimalista, pero también con el hecho de que trabajar en estos espacios supone atraer la atención del espectador hacia detalles de los mismos, el

\footnotetext{
$\overline{{ }^{50} \text { Rainer Work, } 77}$ citado en Ibidem, p. 15: "Cuando comencé a enseñar Trio A a cualquiera que quisiera aprenderlo, con destreza, profesional, gordo, viejo, enfermo, aficionado".

${ }^{51}$ Ibidem, p. 9.

${ }^{52}$ Lippard, Lucy, "La abstracción excéntrica", en Art International, 10 (1966), pp. 34-40.

${ }^{53}$ Poor, Kristin, "Handling Judson's Objects", en Janevski, Ana y Thomas J. Lax (eds.), The Judson Dance Theater: The Work is never done, catálogo de la exposición (Nueva York, MoMA, del 16 de septiembre de 2018 al 3 de febrero de 2019), Nueva York, 2018, p. 77.

${ }^{54}$ Banes, Sally, Terpsichore in Sneakers ... op. cit., p. 85: "Por el contrario nos habla de Primary Accumulation y de que este en ocasiones le produce sentimientos de sexualidad, vulnerabilidad [...], tanto en el bailarín como en el espectador. Lo que Lucy Lippard llama «abstracción sensual» en ciertas obras de arte visual contribuye a la calidad erógena de la danza más que cualquier gesto".
} 
cuerpo y su implicación físico-política en ellos. Esta necesidad de implicación política debería de ser fundamental en un discurso que pretende remarcar la dualidad poético-política de las prácticas de este momento, y más todavía en el Museo Reina Sofía. La importancia que se le da al arte como medio efectivo para la disidencia política hace que, en él, se orienten las lecturas de la colección, en un análisis crítico también enfocado en estos intereses.

Estas lecturas políticas se pueden hacer en toda la sala. Por ejemplo, Trio A, además de primer antecedente de la danza analítica, es icono de la implicación activista del movimiento. Con esta coreografía, Rainer participó en 1967 en la Angry Arts Week en protesta por la guerra de Vietnam y también en el Judson Flag Show (noviembre de 1970), una protesta por el arresto de personas acusadas de profanar la bandera americana. Su contribución fue una versión del Trío $A$ en la que los bailarines vestían solo una bandera estadounidense atada al cuello. Además, coreografió una marcha a través del Soho basada en su M-Walk para manifestarse contra la invasión de Camboya y la masacre de la Universidad de Kent en $1969^{55}$. Por otro lado, Primary Accumulation, de Brown, se asocia con lecturas de género, presentes en multitud de sus obras. Este es el caso de la revisión que André Lepecki hace de It's a Draw/Live Feed, en la que la artista, como hace en Primary Accumulation, desarrolla su danza en el plano horizontal. Lepecki considera este hecho, en conjunción con otras características, una propuesta de "modos de relacionarse con lo horizontal que permiten espacialidades no falocéntricas [...]. En ese sentido en oposición a Pollock [...] derriban el plano de la representación" ${ }^{56}$. Las posiciones feministas deben ser tenidas muy en cuenta y es fundamental generar discursos que pongan de relieve estos posicionamientos, pues la sala se construye a partir de obras de mujeres políticamente posicionadas. Los integrantes del Judson, sobre todo las coreógrafas, participan de la segunda ola feminista tanto en su vida diaria, como en su labor de grupo, trabajando juntas para poder subvertir la autoridad de sus compañeros masculinos y crear diversas formas políticas colectivas antipatriarcales ${ }^{57}$.

Esta salida de la danza hacia el exterior se relaciona también con lo efímero. Joe Goode afirma que la danza "en un entorno motivado por las propiedades del mismo es auténticamente efímera" ${ }^{58}$. Además de esta incursión en el espacio exterior, los coreógrafos del Judson utilizan diversas estrategias para trabajar sobre esta idea, enfatizándola o intentando su superación. Entre estas estrategias se encuentra la complicación extrema del baile para que se produzca

\footnotetext{
${ }^{55}$ Ibidem, p. 15.

${ }^{56}$ Lepecki, André, Agotar la danza. Performance y política del movimiento, Madrid-Barcelona, Centro Coreográfico Gallego-Mercat de les Flors-Aula de Danza Estrella Casero-Universidad de Alcalá, 2008, p. 127.

${ }^{57}$ Janevski, Ana, "The Judson Dance Theater: The Work is never done - Sanctuary Always Needed-", en Janevski, Ana y Thomas J. Lax (eds.), The Judson Dance Theater... op. cit., p. 28.

${ }^{58}$ Goode, Joe, entrevista realizada por Kate Law, "Thinking outside the Black Box. Site-specific Artists Sepeak Their Minds", en Dance magazine (2016), «http://www.bodycartography.org/news/pr.php4?art id=45» [consultado el 20 marzo 2008] citado en Pérez Royo, Victoria, "Danza en contexto. Una introducción", en Pérez Royo, Victoria (ed.), ;A bailar a la calle!: danza contemporánea, espacio público y arquitectura, Salamanca, Ediciones Universidad de Salamanca, 2008, p. 17.
} 
una desaparición instantánea del mismo, como hicieron Rainer en Trio A, Steve Paxton en sus improvisaciones en solitario y Douglas Dunn en Gestures in Red (1978) ${ }^{59}$.

El trabajo del Judson sobre lo efímero se acerca a la sala de los artistas povera. Estos "se abrían a aspectos como lo procesual, lo perecedero, la fragilidad del objeto e incorporaban asimismo un componente performativo" 60 que se combinaba con las lecturas políticas. Estos intereses se materializan en la sala en Le trombe del Giudizio (1968) de Michelangelo Pistoletto, resto de una performance realizada en el estudio del artista en Turín. En esta obra se puede apreciar cómo los artistas povera, frente a los minimalistas, vieron en la teatralidad la capacidad de rescatar el pasado y traerlo al presente en forma de ficción; una herramienta para disolver las diferencias entre la alta y la baja cultura.

Por otro lado, el análisis de esta sala y el trabajo del Judson sobre lo efímero como cualidad ontológica de la danza, nos dirige hacia los planteamientos que se hace el Museo cuando se enfrenta a exponer un arte que tiende a la desaparición. En este sentido, como estrategia museográfica para esta sala, se opta por exponer una combinación de documentos en soporte audiovisual y los dibujos originales de Brown. Estos dibujos evocan formas de notación y dejan entrever la importancia que cobra la partitura en la colección. De la exposición de los vídeos se desprenden planteamientos cercanos a los de Amelia Jones ${ }^{61}$ : gracias a ellos, que son en esencia un documento que recoge en formato audiovisual una coreografía realizada en un espacio y tiempo concretos, se puede crear un relato y estudiar la experimentación corporal y espacial de las coreografías del Judson e incluso deducir la importancia del público y los nuevos planteamientos de la danza en este ámbito. La proyección de estas coreografías conecta también con la idea de archivo que se desarrolla en la colección y que lleva a dar el mismo tratamiento en su exposición al objeto único y al documento ${ }^{62}$. Esto conlleva cierta estetización de la documentación que, como sucede en este caso, llega a convertirse en la obra misma.

\section{Conclusiones}

La investigación presentada en este artículo es bastante concluyente en lo que concierne a sus planteamientos; aunque este apartado puede servir para volver sobre cuatro problemas fundamentales.

El primero de estos problemas es el rol que asumen los museos españoles en el proceso de musealización de la danza. El artículo revela, al remarcar la importancia que adquieren en el

\footnotetext{
${ }^{59}$ Banes, Sally, Terpsichore in Sneakers... op. cit., p. 45.

${ }^{60}$ Borja-Villel, Manuel J. et al., La colección... op. cit., p. 116.

${ }^{61}$ Jones, Amelia, "Presence in Absentia... op. cit.

${ }^{62}$ Hinojosa, Lola ,"Museo y acontecimiento... op. cit., p. 26.
} 
Reina Sofía las generaciones del Judson Dance Theater y la Nueva Danza que, en estos procesos, los museos españoles más que considerarse como un espacio para la experimentación, - como lo eran los primeros museos que, entre 1940 y 1990, acogieron nuevas formas dancísticas-, consolidan su papel como institución legitimadora y conservadora de la historia al privilegiar estas propuestas ya consolidadas en el panorama internacional.

El segundo deriva de la relación de la danza con el espectáculo y el entretenimiento y su exclusión de la historia del arte oficial, que implican que los discursos que genera el Museo en torno a la misma estén restringidos a aquellas cualidades que la ligan al arte visual, utilizando las imbricaciones entre ambas como una justificación de la entrada de la danza en la institución. Al remarcar las interpretaciones que se podrían hacer de la sala del Judson poniendo el foco en la propia historia y condiciones de la disciplina no se está señalando como erróneo el discurso curatorial escogido por el Museo, sino que se intenta poner de relieve la existencia de puntos de vista que se alejan de este ejercicio al que acostumbran los espacios museísticos.

Por último, la imposibilidad de aunar teoría y práctica, que conlleva a su vez multitud de trabas. En este sentido, la investigación que el Reina Sofía desarrolla en el campo teórico es el principal valor del Museo para con esta forma artística y un punto de partida idóneo para que, en un futuro, la danza pueda adquirir más presencia en la institución. Sin embargo, las cuestiones que en su labor teórica emprenden de lleno no acaban reflejándose en la práctica. Al abordar con cierto recelo las tensiones que se desprenden de las relaciones entre la danza y la institución, se acaba generando una jerarquía que sigue relacionando la danza con formas derivadas del espectáculo y el entretenimiento, y considera el archivo tradicional más capacitado para generar discursos presentados en colecciones y exposiciones temporales. En ellas, la presentación de danza en formato audiovisual es lo más común, aunque también conlleva riesgos. Entre ellos, el ya mencionado desvanecimiento de las fronteras entre la obra de arte y su documentación o los que implican introducir una obra con una duración interna propia en sala, más si se reproducen las piezas sucesivamente. Sería ideal dar una solución curatorial a la problemática que esto ocasiona en la sala del Judson; aunque, sin conocer los recursos materiales que el Museo dispone, solo se puede realizar una propuesta para solventar la imposibilidad del espectador de reconocer la obra que se encuentra en pantalla. Esta es simple pues solo requiere incluir en la parte inferior de cada vídeo, durante toda su extensión, una referencia a la coreografía que el espectador está viendo en ese momento, así sabrá continuamente ante qué pieza se encuentra.

En ocasiones, estos planteamientos teóricos no pueden ponerse en práctica debido a los problemas que debe sortear la institución. El más acuciante de estos es el económico, reflejado, entre otras muchas cosas, en la imposibilidad de incluir en las colecciones la danza en vivo, ya que su mantenimiento en el tiempo sería insostenible. Este problema también se percibe en las programaciones, que en ocasiones deben adaptarse a las de festivales o espacios escénicos 
201 Blanca Molina Olmos, "Bailando en el Museo Reina Sofía. El Judson Dance Theater...”

con los que la institución ha establecido convenios que le permiten trabajar con coreógrafos y compañías de danza compartiendo costes.

Todas esas trabas son por las que la danza, sobre todo la danza en vivo, no llega a un mayor grado de institucionalización y queda relegada a discursos que la constriñen, sigue manteniendo el apelativo de actividad y se aísla en la caja negra anexa al museo. A pesar ello, s que el museo es un espacio legítimo para la danza, el cual debe aceptar los retos que esta le propone y que sin duda implica cambiar completamente sus modos de hacer. 